\title{
Um olhar aos núcleos temáticos em Modelagem Matemática que emergiram dos trabalhos do VII SIPEM
}

\author{
Lilian Akemi Kato \\ Wellington Piveta Oliveira
}

\section{Resumo}

Neste artigo discorremos sobre as pesquisas brasileiras em Modelagem Matemática na Educação Matemática. A partir da questão: "Que núcleos temáticos da pesquisa em Modelagem Matemática emergem dos trabalhos apresentados no VII SIPEM?”, analisamos os artigos que foram publicados pelo Grupo de Trabalho 10 - "Modelagem Matemática" na VII edição do SIPEM. Esse olhar se caracterizou como uma pesquisa qualitativa de cunho descritiva e interpretativa e, ao refletirmos sobre os cinco núcleos temáticos emergentes, dialogamos com as tendências temáticas da pesquisa em Modelagem Matemática apresentadas por Oliveira, A. (2016). Em linhas gerais, em relação a essas tendências temáticas, registramos alguns avanços como, por exemplo, nas reflexões sobre a formação de professores, porém, poucas discussões ainda a respeito de materiais curriculares para práticas pedagógicas em Modelagem Matemática. Nossa reflexão sobre esses núcleos revelou preocupações já explicitadas em pesquisas internacionais, o que indica um movimento convergente do debate sobre os temas interligados à Modelagem Matemática como prática e linha de investigação no Brasil e outros países.

Palavras-chave: Educação Matemática. Ensino. Pesquisa sobre Modelagem Matemática na Educação. 


\title{
A look at the thematic nuclei in Mathematical Modelling that emerged from the work of VII SIPEM
}

\author{
Lilian Akemi Kato \\ Wellington Piveta Oliveira
}

\begin{abstract}
In this paper we discuss about Brazilian scientific researches on the topic of Mathematical Modeling. By asking the question "Which thematic cores in researches of Mathematical Modeling emerge from the annals of the $7^{\text {th }}$ SIPEM?", we analyze all published papers belonging to Group 10 "Mathematical Modeling" in the aforementioned event. Thus, our analytical approach adopts a qualitative perspective of descriptive and interpretative nature. Upon reflection of the five emerging thematic cores, it was possible to establish a connection with the thematic tendencies of research on Mathematical Modeling as presented by A. Oliveira (2016), whose focus rests in said area. In general, some advances related to these thematic tendencies were also observed, especially on the subject of teacher training; on the other hand, few discussions have been noted concerning curricular materials for pedagogical purposes in Mathematical Modeling. Our reflection on these cores revealed expressed concerns that are akin to those of other international studies. This serves to show a converging movement pertaining to the debate of topics related to Mathematical Modeling in pragmatic and academic levels in Brazil and other countries.
\end{abstract}

Keywords: Mathematics Education. Mathematics Teaching. Research on Mathematical Modeling in Education. 


\section{Considerações iniciais}

Nas últimas décadas tem sido expressivo o número de pesquisas sobre a Modelagem Matemática na Educação Matemática55. Os esforços empreendidos em investigar diferentes aspectos, envolvendo desde compreensões sobre a Modelagem Matemática e sua presença na sala de aula, estendendo-se à prática pedagógica, tem sido alguns dos vários temas abordados por diferentes pesquisadores revelados nessas produções.

Reflexões sobre esses aspectos também se mostram presentes na pesquisa realizada por Oliveira, A. (2016), na qual analisou os trabalhos publicados pelo Grupo de Trabalho (GT) 10 - "Modelagem Matemática" nas edições do Seminário Internacional de Pesquisa em Educação Matemática (SIPEM)(2003 a 2015), apresentando algumas tendências na pesquisa brasileira sobre Modelagem Matemática, por exemplo, sobre: aspectos teóricos e epistemológicos; práticas pedagógicas; formação de professores; materiais curriculares (educativos); e, revisão sistemática de estudos. Essas tendências expõem sobre os vários fenômenos investigados pela comunidade brasileira de pesquisadores em Modelagem Matemática.

Assim como o estudo realizado por Oliveira, A. (2016), outros pesquisadores como Silveira (2007), Araújo (2009), Klüber e Burak (2014), Klüber et. al. (2015), também se preocuparam em explicitar a trajetória da pesquisa em Modelagem Matemática apontando algumas projeções, assim como, sustentaram a importância da realização de estudos sistemáticos, mapeamentos, meta-pesquisas, entre outras denominações para que o campo de estudos seja compreendido, como também afirmaram Barbosa, Araújo e Caldeira (2009, p. 56, destaque dos autores), sobre "a necessidade de mais estudos que busquem gerar metacompreensões sobre o 'campo de modelagem matemática', oferecendo assim subsídios para que o próprio campo possa refletir sobre seus desenvolvimentos”, indicando caminhos que ainda podem ser percorridos.

Entendemos que estudos dessa natureza são importantes para que esforços sejam depositados em investigações que sejam relevantes para o fortalecimento das bases teóricoepistemológicas da Modelagem Matemática. E, é reconhecendo a importância desses estudos e, com o intuito de ampliarmos esse olhar sobre as pesquisas brasileiras em Modelagem Matemática que apresentamos esse trabalho, investigando acerca dos focos temáticos que emergiram dos trabalhos publicados no GT 10 - "Modelagem Matemática" da última edição do SIPEM, a sétima (VII SIPEM).

$\mathrm{Na}$ oportunidade, nos inteiramos de outros estudos da literatura de Modelagem Matemática, trazendo algumas reflexões acerca dos temas perseguidos nas pesquisas desenvolvidas. Para que essas reflexões pudessem ser empreendidas, indicamos na seção

55 Para evitar repetições, utilizaremos apenas Modelagem Matemática.

ISSN 2526-2882 
seguinte, o modo pelo qual procedemos essa investigação, desvelando os encaminhamentos metodológicos.

\section{Aspectos metodológicos}

Na busca pelos materiais relevantes ao escopo dessa pesquisa, a leitura empreendida, o destaque de aspectos relevantes a serem considerados e a reflexão sobre o que eles revelam, é um percurso que expressa ressonâncias à abordagem qualitativa de pesquisa, na medida em que descrevemos e interpretamos os dados emergentes (DENZIN; LINCOLN, 2006).

Esse movimento foi conduzido pela interrogação: “Que núcleos temáticos da pesquisa em Modelagem Matemática emergem dos trabalhos apresentados no VII SIPEM?”. Ao refletirmos sobre essa interrogação, buscando caminhos possíveis dos lócus de manifestação desses núcleos, nos reportamos aos artigos publicados no VII SIPEM. Destacamos o SIPEM porque esse evento mostra-se como "[...] uma das atividades mais importantes da SBEM56 ao possibilitar que a produção [de Educação Matemática] brasileira seja mais conhecida” (SBEM, 2019, inserção nossa). O SIPEM é um evento internacional promovido pela SBEM, que promove a interação entre estudos e respectivos pesquisadores da Educação Matemática, de diferentes grupos. Nesse sentido, o SIPEM foi proposto na expectativa de:

[...] divulgar as pesquisas brasileiras e promover o encontro dos pesquisadores que a elas se dedicam, proporcionando-lhes a possibilidade de conhecer as investigações que estão sendo realizadas em diferentes instituições. Além disso, o SIPEM propicia a formação de grupos integrados de pesquisa, ao congregar pesquisadores brasileiros e estrangeiros o que possibilita o avanço das pesquisas em educação matemática em nosso país (SBEM, acesso 28 de maio de 2019).

Entendemos que como o SIPEM constitui-se em um espaço para discussão e socialização de produções realizadas por pesquisadores, expressando o movimento da pesquisa em Educação Matemática no Brasil, um olhar dirigido para as produções nele publicados se mostra relevante. Na sétima edição do SIPEM, que ocorreu em novembro de 2018 na cidade de Foz do Iguaçu, Estado do Paraná, foram aceitos e publicados 17 textos sobre Modelagem Matemática no GT10 - "Modelagem Matemática”, submetidos por alguns dos grupos de pesquisa dedicados ao debate sobre essa temática.

Destacamos que as nossas análises foram empreendidas com base nessas produções por compreendermos que, de algum modo, no escopo da produção científica desta edição do SIPEM, elas expressam uma interlocução entre os grupos de pesquisas em Modelagem Matemática no Brasil. É importante esclarecermos que na oportunidade dessa interlocução, também participamos junto aos autores e debatedores das discussões dos textos no GT, nesta

${ }^{56}$ Sociedade Brasileira de Educação Matemática. 
sétima edição do evento. Sobre esses trabalhos, o "Quadro 1" expressa os títulos, os autores e os respectivos códigos que atribuímos a cada uma dessas 17 produções.

Quadro 1 - Trabalhos aceitos e publicados no GT1o - "Modelagem Matemática" da VII edição do SIPEM.

\begin{tabular}{|c|c|c|}
\hline Títulos & Autor(es) & Código \\
\hline $\begin{array}{l}\text { Conhecimento Matemático para o ensino propiciado pelo } \\
\text { desenvolvimento de atividades de Modelagem }\end{array}$ & $\begin{array}{l}\text { BISOGNIN; } \\
\text { BISOGNIN }\end{array}$ & T1 \\
\hline $\begin{array}{l}\text { O que dizem as CNMEM's sobre as atividades de Modelagem na } \\
\text { Educação Básica }\end{array}$ & $\begin{array}{l}\text { MALHEIROS; } \\
\text { FORNER }\end{array}$ & T2 \\
\hline $\begin{array}{l}\text { Modelagem Matemática e currículo: um caminho entre as } \\
\text { situações-limites e os inéditos-viáveis }\end{array}$ & $\begin{array}{l}\text { FORNER; } \\
\text { MALHEIROS }\end{array}$ & $\mathrm{T} 3$ \\
\hline $\begin{array}{l}\text { Práticas pedagógicas de professores da Educação Básica num } \\
\text { contexto de formação continuada em MM na Educação } \\
\text { Matemática }\end{array}$ & MUTTI; KLÜBER & $\mathrm{T} 4$ \\
\hline Sobre ensinar e aprender 'o fazer' Modelagem Matemática & $\begin{array}{l}\text { ALMEIDA; SILVA; } \\
\text { RAMOS }\end{array}$ & $\mathrm{T} 5$ \\
\hline $\begin{array}{l}\text { As práticas com Modelagem Matemática na Educação Básica do } \\
\text { Paraná: um olhar }\end{array}$ & $\begin{array}{l}\text { BURAK; } \\
\text { PENTEADO }\end{array}$ & T6 \\
\hline Aprendizagem colaborativa em Modelagem Matemática & $\begin{array}{l}\text { SILVA; BORSSOI; } \\
\text { FERRUZZI }\end{array}$ & $\mathrm{T}_{7}$ \\
\hline $\begin{array}{l}\text { A atuação do formador-formando num contexto de formação } \\
\text { continuada de professores em MM na Educação Matemática }\end{array}$ & $\begin{array}{l}\text { KLÜBER; } \\
\text { TAMBARUSSI }\end{array}$ & $\mathrm{T} 8$ \\
\hline $\begin{array}{l}\text { A inteiração e a matematização em atividades de Modelagem } \\
\text { Matemática }\end{array}$ & $\begin{array}{l}\text { MENDES; } \\
\text { OLIVEIRA }\end{array}$ & $\mathrm{T} 9$ \\
\hline Professor, a aula hoje vai ser de Matemática ou de Modelagem? & $\begin{array}{l}\text { ARAÚJO; } \\
\text { MELILLO }\end{array}$ & T10 \\
\hline $\begin{array}{l}\text { Reflexiones sobre metodología crítica en ambientes de Modelación } \\
\text { Matemática: dos investigaciones en el contexto colombiano }\end{array}$ & $\begin{array}{l}\text { MANCERA; } \\
\text { CAMELO; ARAÚJO }\end{array}$ & T11 \\
\hline $\begin{array}{l}\text { A matematização na articulação entre regras e experimentação } \\
\text { empírica em atividades de Modelagem Matemática }\end{array}$ & ALMEIDA; SOUSA & T12 \\
\hline $\begin{array}{l}\text { Práticas de Ensino com Modelagem Matemática: influências de } \\
\text { momentos vivenciados na formação inicial }\end{array}$ & $\begin{array}{l}\text { BRAZ; OLIVEIRA; } \\
\text { KATO }\end{array}$ & $\mathrm{T} 13$ \\
\hline $\begin{array}{l}\text { Um estado da arte de pesquisas acadêmicas sobre Modelagem em } \\
\text { Educação Matemática (de } 1979 \text { a 2015) }\end{array}$ & SOARES; IGLIORI & T14 \\
\hline $\begin{array}{l}\text { O papel da informática no desenvolvimento de uma atividade de } \\
\text { Modelagem Matemática }\end{array}$ & MENEZES; BRAGA & T15 \\
\hline $\begin{array}{l}\text { Criatividade e MM: o que dizem alunos egressos de um curso de } \\
\text { Licenciatura em Matemática sobre suas formaçoses iniciais }\end{array}$ & VERTUAN & T16 \\
\hline $\begin{array}{l}\text { Modelos Matemáticos em Atividades de Modelagem Matemática: } \\
\text { uma terapia filosófica }\end{array}$ & $\begin{array}{l}\text { SOUSA; TORTOLA; } \\
\text { SILVA }\end{array}$ & T17 \\
\hline
\end{tabular}

Fonte: Os autores (2019), anais do SIPEM

Tendo acesso a cada uma delas, efetuamos uma primeira leitura. Consideramos que essa primeira leitura foi mais num sentido exploratório, isto é, para que pudéssemos conhecer sobre quais os autores dos textos e o que versaram cada um deles. Na sequência, realizamos outra leitura para que, de modo atento, pudéssemos indicar os focos temáticos desses textos.

Iluminados pela interrogação: "Que núcleos temáticos da pesquisa em Modelagem Matemática emergem dos trabalhos apresentados no VII SIPEM?”, destacamos desses textos, alguns aspectos que nos permitiram dizer dos focos temáticos (FT) de cada um deles. Desse modo, esse exercício permitiu com que estabelecêssemos algumas unidades de análise que 
entendemos serem expressivas desses FT. A seguir, no "Quadro 2" apresentaremos essas unidades de análise:

Quadro 2 - Unidades de análise expressando os focos temáticos dos trabalhos analisados.

\begin{tabular}{|c|c|}
\hline Focos temáticos & FTs \\
\hline $\begin{array}{l}\text { Analisaram a mobilização de conhecimento matemático para o ensino (conhecimento } \\
\text { pedagógico do conteúdo do professor), na elaboração de atividades (de Modelagem), } \\
\text { construídas por } 12 \text { professores mestrandos, em formação continuada. }\end{array}$ & FT1 \\
\hline $\begin{array}{l}\text { Analisaram as práticas de Modelagem em sala de aula, relatadas nas últimas quatro } \\
\text { edições da CNMEM, problematizando a natureza das atividades a partir de três } \\
\text { categorias, Planejamento da Atividade, Concepção de Modelagem e } \\
\text { Desenvolvimento das Atividades. }\end{array}$ & FT2 \\
\hline $\begin{array}{l}\text { Os autores refletem sobre possíveis relações entre a Modelagem e o currículo, que são } \\
\text { (ou não) estabelecidas durante a elaboração de atividades de Modelagem por } \\
\text { professores, colaborativamente, em formação continuada. Para isso, indicam a } \\
\text { superação de situações-limites como algo que pode ser superado por meio a promoção } \\
\text { de inéditos-viáveis como a constituição de grupos de professores para elaboração de } \\
\text { atividades. }\end{array}$ & FT3 \\
\hline $\begin{array}{l}\text { Discorreram sobre as práticas pedagógicas de Modelagem de alguns professores da } \\
\text { Educação Básica, participantes de um grupo de Formação Continuada em } \\
\text { Modelagem. A pesquisa reúne de modo sistemático, os resultados da pesquisa de } \\
\text { Mestrado de Mutti (2016), discutindo as categorias emergentes sobre práticas } \\
\text { pedagógicas, ao analisarem discursos e ações desses professores. }\end{array}$ & $\mathrm{FT}_{4}$ \\
\hline $\begin{array}{l}\text { À luz da teoria de Pierce, analisaram a relação de signos produzidos no processo } \\
\text { comunicacional entre utterer e intérprete, respectivamente, professora e estudantes, } \\
\text { em três episódios que ocorreram na componente de Modelagem de um curso de } \\
\text { Licenciatura em Matemática, com o objetivo de mostrarem a possibilidade de ensinar } \\
\text { e aprender 'o fazer' Modelagem. }\end{array}$ & FT5 \\
\hline $\begin{array}{l}\text { Os autores investigaram } 31 \text { trabalhos que versaram sobre as práticas de Modelagem } \\
\text { desenvolvidas em escolas paranaenses, publicadas nos Anais dos EPMEM’s de } 2004 \\
\text { a 2014, com o objetivo de caracterizá-las e, tecer considerações sobre suas implicações } \\
\text { para o ensino e aprendizagem. }\end{array}$ & FT6 \\
\hline $\begin{array}{l}\text { Analisaram, no desenvolvimento de uma atividade de Modelagem, a aprendizagem } \\
\text { colaborativa manifesta da interação de estudantes da Licenciatura em Química, em } \\
\text { ambiente virtual e presencial. }\end{array}$ & $\mathrm{FT}_{7}$ \\
\hline
\end{tabular}


Analisaram em 4 dissertações, a relação do formador-formando na formação continuada de professores, indicando que se estabelece uma relação de parceria e apoio, que pode subsidiar (durante), encorajar à realização de práticas de Modelagem e, que essa relação de cumplicidade mútua é essencial ao desenvolvimento de propostas de formação em Modelagem Matemática.

Investigaram como a inteiração e a matematização interferem na resolução de atividades de Modelagem enquanto alternativa pedagógica, analisando atividades que foram desenvolvidas por estudantes da Licenciatura em Matemática.

Teceram reflexões sobre o paralelismo como categoria resultante da Tese de Melillo (2017), como um modo de discutir sobre o dualismo entre a prática com a Modelagem Matemática e a prática na aula de Matemática, no contexto da formação técnica/formação geral, promovida pelos Institutos Federais.

Analisaram os dados provenientes de duas teses, com a intenção de refletirem sobre a investigação crítica e investigação de possibilidades, sendo esta oriunda de um ambiente de Modelagem na perspectiva sócio-crítica (a produção dos dados foi coletado da criação de ambientes de Modelagem, em Bogotá - Colômbia), apontando que há forte relação da prática investigava nesse contexto.

Analisaram como as regras e a experimentação empírica, são articuladas na matematização em atividades de Modelagem, analisando uma atividade realizada por estudantes na componente de EDO da Licenciatura em Matemática.

Explicitaram sobre a vivência de alguns momentos na formação inicial do professor com a Modelagem, mediante a análise de duas práticas de Modelagem quando duas futuras professoras realizaram o TCC.

Consiste em uma pesquisa que promove o Estado da Arte, reunindo dissertações e teses desenvolvidas em Programas de pós-graduação stricto sensu, as quais tematizaram sobre Modelagem, no período de 1979 a 2015, como forma de exemplificar um possível caminho para realizar esse tipo de pesquisa.

O estudo apresentou parte dos resultados de uma Dissertação de Mestrado. Os autores buscaram caracterizar o papel da informática no desenvolvimento de uma atividade de Modelagem, realizada por três estudantes da Licenciatura em Matemática.

Investigaram "o que alunos egressos de um curso de Licenciatura em Matemática manifestam sobre modelagem matemática e criatividade no contexto de suas formações iniciais?”, por meio da análise de um questionário.

Colocaram em "terapia" a ideia de modelo matemático, a partir da análise de atividades de Modelagem realizadas por estudantes da Licenciatura em Química e Licenciatura em Matemática, sob a interrogação: como os diferentes usos de modelos matemáticos em atividades de modelagem matemática se articulam na sistematização de conteúdos no ambiente escolar? 
A articulação de cada uma das unidades de análise, as quais expressaram os FT relativas as produções publicadas no GT10 - "Modelagem Matemática”, foi interpretada à luz da interrogação estabelecida, buscando pelos sentidos emergentes dessas unidades de análise, a fim de que pudéssemos ter clareza dos FT das produções. Assim, reunimos os FT, segundo um exercício de convergências-divergências entre os sentidos emergentes, um movimento de agrupar esses sentidos manifestos como FT. Esse processo de articulação dos sentidos permitiu que estabelecêssemos uma categorização dos respectivos FT que foram colocados em evidência.

Foi desse movimento que emergiram os núcleos temáticos sobre a pesquisa em Modelagem Matemática, à medida que fomos atribuindo nomes à cada um deles com base nesta reunião dos sentidos emergentes que revelaram os FT das unidades de análise articuladas, resultante do movimento acima descrito. Esse processo pode ser visualizado na "Figura 1", a seguir, quando indicamos a convergência dos FT, que deu origem a cada um dos núcleos:

Figura 1 - Movimento de constituição dos núcleos temáticos da pesquisa em Modelagem Matemática.

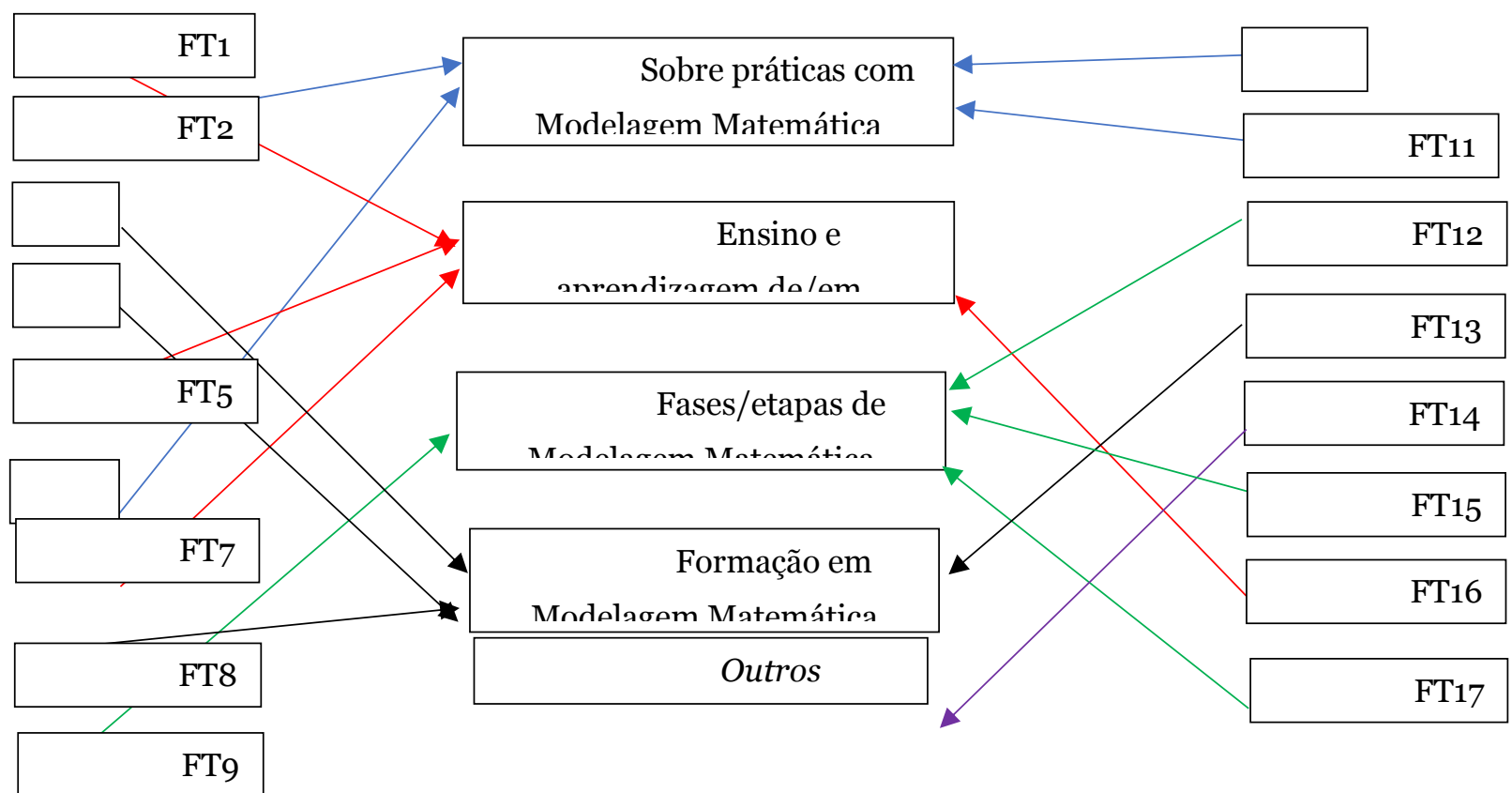

Fonte: Os autores (2019).

A partir da explicitação sobre o modo pelo qual chegamos aos núcleos temáticos emergentes, a saber: i) sobre práticas com Modelagem Matemática; ii) ensino e aprendizagem em/de Modelagem Matemática; iii) fases/etapas de Modelagem Matemática; iv) formação em Modelagem Matemática; v) outros, na sequência, apresentamos as respectivas descrições de cada um, das quais emergiram reflexões sobre o que esses núcleos expressam acerca da pesquisa brasileira em Modelagem Matemática, como também se mostra à compreensão dos 
“caminhos trilhados" pela comunidade de Modelagem Matemática, ao nos inteirarmos das pesquisas desenvolvidas, em especial, da pesquisadora Oliveira, A. (2016).

\section{Sobre os núcleos temáticos da pesquisa brasileira em Modelagem Matemática a partir dos trabalhos do VII SIPEM}

[...] a distância entre o ambiente normal e habitual de ensino e aprendizagem em sala de aula - para professores e alunos - e a necessidade de envolvimento em modelagem matemática aumenta o desafio da implementação pelo professor e a resolução bem-sucedida pelos alunos (BROWN; IKEDA, 2019, p. 235, tradução nossa).

A citação precedente parece convergir para o cerne das finalidades das pesquisas no campo da Modelagem no âmbito da Educação Matemática. Nesse viés, trazemos essa reflexão à discussão a partir dos núcleos temáticos emergentes. Portanto, a seguir, descrevemos acerca dos núcleos temáticos surgidos do movimento de pesquisa, momento em que interrogamos sobre seus significados no contexto da produção científica brasileira em Modelagem Matemática. Esclarecemos que esses núcleos temáticos não são idiossincráticos, eles se complementam quando voltamos para dos interesses dos pesquisadores em Modelagem Matemática.

No tocante ao primeiro núcleo, “i) sobre práticas com Modelagem Matemática", embora os trabalhos abordaram diferentes discussões, um aspecto comum entre eles é a preocupação com a prática com Modelagem Matemática. O FT2, por exemplo, ao analisar as práticas com Modelagem Matemática relatadas nos trabalhos publicados nas edições da Conferência Nacional sobre Modelagem na Educação Matemática (CNMEM) e identificar aspectos relacionados ao planejamento da atividade, às concepções de Modelagem emergentes e, o desenvolvimento dessas atividades e, de modo semelhante, o FT6 ao se centrar nas características das práticas com Modelagem Matemática relatadas nos relatos de experiências publicados nas edições do Encontro Paranaense sobre Modelagem na Educação Matemática (EPEMEM), deixam evidentes a preocupação com a busca de esclarecimentos ou, de compreensões sobre que e como práticas com Modelagem Matemática têm sido desenvolvidas.

Ao refletir sobre a prática com Modelagem Matemática em relação prática de rotina nas salas de aula de Matemática, o FT1o constata uma dualidade relacionada a ideia de paralelismo entre essas duas práticas. Esse foco indica a distância da prática com Modelagem Matemática nas salas de aula, quando os estudantes sujeitos da pesquisa manifestaram ser a prática com Modelagem Matemática como outra prática que não aula de Matemática, isto é, nos parece que eles deveriam compreendê-las como constituintes.

Esse núcleo reuniu ainda o FT11, que ao sugerir criação de situações como ambientes de Modelagem Matemática na perspectiva sócio-crítica, decorrente da reflexão sobre as 
situações atuais em direção às situações ideias, apontou que há uma aproximação da prática pedagógica|investigativa nesses contextos, o que indica potencialidades desses ambientes ao se pensar num projeto de educar matematicamente. Para nós, esse FT atende a um dos aspectos agendados na pesquisa de Oliveira, A. (2016, p. 39, destaque nosso):

Estudos sobre as perspectivas sobre modelagem e suas implicações nas práticas Pedagógicas; neste primeiro ponto, a partir do trabalho de Kaiser e Sriraman (2006), pesquisas podem investigar as implicações para a prática de modelagem ao professor assumir diferentes perspectivas. Afinal, diferentes perspectivas geram diferentes modos de fazer modelagem (BARBOSA, 2009).

Esse núcleo permitiu-nos identificar diferentes enfoques sobre a pesquisa em Modelagem Matemática no tocante à prática pedagógica, pois, há produções cujo foco é interrogar essa prática, com vistas a estabelecer compreensões sobre ela, como também, há aqueles que refletem sobre diferentes aspectos de práticas que foram empreendidas. Isso nos mostra que a "[...] pesquisa educacional possui essa interface com a ação pedagógica" (KLÜBER et al, 2015, p. 91). Reconhecemos que discussões a respeito da prática são acentuadas na comunidade de Modelagem Matemática, pois, em geral, ainda que outros FT tenham dado sentido à existência de outros núcleos, a prática pedagógica com Modelagem Matemática tem sido promovida e tomada como instrumento para análise sob diferentes perspectivas teóricas, na intenção de se compreender distintos fenômenos.

De modo articulado, o segundo núcleo, "ii) ensino e aprendizagem em/de Modelagem Matemática”, emerge das produções que investigaram sobre o processo de ensino e de aprendizagem em práticas com Modelagem Matemática, refletindo sobre a possibilidade de mobilizar conhecimentos matemáticos em práticas com Modelagem Matemática (FT1), bem como, da possibilidade de se ensinar e de aprender o "fazer" Modelagem Matemática (FT5). Esses focos ilustram, respectivamente, o nome atribuído ao núcleo, já que o primeiro foco diz da possibilidade de aprender em Modelagem Matemática e, o segundo, do ensino e aprendizagem sobre o “fazer”, isto é, nos remete à compreensão sobre Modelagem Matemática.

Além disso, o $\mathrm{FT}_{7}$ destacou a possibilidade de aprender colaborativamente no contexto da Modelagem Matemática e o FT16, expressou que a Modelagem Matemática permite o desenvolvimento de ações criativas, isto é, indicando que o processo de ensino e aprendizagem com a Modelagem Matemática, por exigir entre outras coisas, a autonomia, não ter resposta única, utilizar de atividades experimentais, propicia criticidade e estimula a criatividade. Embora esse último FT tenha sido articulado a esse núcleo, por trazer à tona reflexões direcionadas ao processo de ensino e aprendizagem oriundas da vivência com a Modelagem Matemática na formação inicial de professores, entendemos que o assunto "criatividade" investigado se mostra inédito no âmbito do SIPEM, do modo como propôs o 
estudo. Estes, assim como outros temas, indicam que ainda há um terreno amplo para ser explorado no campo da Modelagem Matemática.

Assim, afirmamos que os aspectos que constituíram ambos os núcleos temáticos emergentes, “i) sobre práticas com Modelagem Matemática” e "ii) ensino e aprendizagem em/de Modelagem Matemática”, se aproximaram de uma das tendências temáticas explicitadas na pesquisa desenvolvida por Oliveira, A (2016), a saber: modelagem matemática nas práticas pedagógicas. Segundo a autora, essa tendência “[...] reúne estudos com foco de análise na modelagem em situações de ensino e aprendizagem da Matemática na educação básica e superior" (idem, p. 36).

Essas reflexões acerca da prática pedagógica com Modelagem Matemática e do processo de ensino e aprendizagem decorrentes dessa prática são temas debatidos desde a emergência da Modelagem no âmbito da Educação Matemática. Nesse sentido, é compreensível que elas ocorram de modo permanente, uma vez que os avanços e/ou retrocessos da pesquisa impactam, diretamente, nas práticas empreendidas e vice-versa, então, a recorrência desses estudos expressam o próprio movimento de constituição e de validação dos argumentos para área.

No que diz respeito ao terceiro núcleo, "iii) fases/etapas de Modelagem Matemática”, os focos temáticos convergiram para a investigação de algum aspecto do processo de modelar matematicamente, segundo fases, etapas, ou ainda, encaminhamentos da Modelagem Matemática. O FT9, por exemplo, interrogou sobre como as etapas de interação e matematização em atividades de Modelagem Matemática influenciam na resolução apresentada pelos estudantes.

O FT12, buscou saber como as regras e a experimentação empírica se articulam na etapa da matematização da atividade de Modelagem Matemática. Já o FT15, tratou sobre à caracterização da informática nas decisões das estudantes ao desenvolverem alguma atividade de Modelagem Matemática; e, o FT17 investigou a utilização de modelos matemáticos em atividades de Modelagem Matemática indicando, que o uso deles decorre de modo descritivo, prescritivo, e explicativo, de acordo com o envolvimento da pessoa com o fenômeno.

Embora os FTs tenham apresentado aspectos distintos relacionados ao processo da modelagem, de algum modo, eles fazem referência às fases/etapas ou, encaminhamentos da Modelagem Matemática em consonância com o que encontramos na literatura em relação à existência de alguns caminhos que conduzem ao processo problematização e investigação, com vista às compreensões a respeito do fenômeno investigado.

A manifestação desse núcleo nos mostra que a compreensão do processo de modelar matematicamente é amplo e admite a exploração de diferentes aspectos que o constitui. Talvez, isso tenha relação com os diferentes modos pelos quais a Modelagem Matemática tem sido 
compreendida pela comunidade brasileira, já que eles têm sido sustentados em diferentes perspectivas.

Inferimos que esse núcleo se articula com a tendência temática apontada por Oliveira, A. (2016), intitulada aspectos teóricos e epistemológicos da Modelagem Matemática, uma vez que a autora analisou que as pesquisas que congregaram essa tendência, investigaram além de outras coisas, sobre "[...] o papel dos modelos matemáticos, discutiram sobre a natureza dos problemas e sobre as hipóteses e pressupostos assumidos na construção da solução do problema" (idem, p. 36), indicando proximidade com os focos por nós analisados. Ainda, de modo particular, destacamos que o FT15 ao relacionar a prática com Modelagem Matemática à tecnologia, acena para um dos itens agendados pela autora supracitada sobre a demanda de "estudos que discutam o papel das tecnologias digitas no processo de fazer modelagem; o sexto ponto refere-se as pesquisas que explorem a presença das tecnologias digitais no processo de fazer modelagem” (ibidem, p. 40, destaque nosso).

Do movimento empreendido na pesquisa, o quarto núcleo temático expressou algumas compreensões sobre a "formação em Modelagem Matemática", isto é, a relação da pesquisa em Modelagem Matemática com a formação de professores, para a formação dos professores. O FT3, por exemplo, explicitou sobre caminhos para que algumas situaçõeslimites possam ser conduzidas à inéditos-viáveis, como a constituição de coletivos de formação, de tal modo que a Modelagem Matemática seja incorporada às práticas pedagógicas.

$\mathrm{Na}$ mesma linha, o FT4 ao interrogar sobre as práticas pedagógicas com Modelagem Matemática de professores participantes de uma formação continuada, revelou que para a adoção da Modelagem Matemática, condições que impulsionem e garantam a permanência dos professores num novo estilo devem ser pensadas, assim como, a constituição de um coletivo de pensamento próprio da Modelagem. Nesse contexto de discussão, emerge o FT8 quando interrogou a atuação de formadores-formandos, indicando que durante a formação do professor, a relação de parceria, cumplicidade, proximidade, e de apoio, de encorajamento, são aspectos relevantes para que práticas de Modelagem Matemática sejam empreendidas por professores. Já o FT13, ao acompanhar a prática de duas futuras professoras, apontaram que a vivência de diferentes momentos com a Modelagem Matemática na formação inicial, conferiu segurança e incentivo ao empreendimento de práticas com Modelagem Matemática por elas.

No estudo realizado por Oliveira, A. (2016), as produções relativas à temática modelagem matemática na formação de professores, de modo geral, buscaram “[...] entender a inserção da modelagem em cursos de formação de professores de modo a viabilizar sua implementação no contexto escolar" (idem, p. 37).

Diante disso, compreendemos que nesta edição do SIPEM, os trabalhos indicaram outros aspectos como, por exemplo, aqueles cujo fenômeno de discussão se deu no solo da Formação de Professores de Matemática, ocorrendo práticas com Modelagem Matemática; 
aqueles cujo fenômeno é/se relaciona à Formação de Professores em Modelagem Matemática; e, aqueles que está dirigido para a Formação de Professores. Oliveira, A. (2016), ao agendar que podem ser desenvolvidos:

estudos que abordem ações realizadas na formação inicial e continuada para viabilizar o contado com a modelagem; o segundo ponto diz respeito aos estudos que investiguem a natureza dos cursos para a formação inicial e continuada sobre modelagem. Pesquisas que analisem ações que são propostas nos cursos e suas repercussões na formação e nas práticas pedagógicas (idem, p. 39-40, destaque nosso).

Compreendemos que há avanços do ponto de vista teórico, no tocante aos olhares para a Formação de Professores em Modelagem Matemática, quando os FTs que constituíram esse núcleo temático caminharam na direção do pensar sobre essa formação, investigando aspectos que se dirigem à explicitação do ser Formação em Modelagem Matemática. Para nós, essa articulação da Formação em Modelagem Matemática converge para o que outras pesquisas têm registrado sobre ser um debate relativamente recente na área (TAMBARUSSI; KLÜBER, 2014, OLIVEIRA, W.; KLÜBER, 2017), dando-nos abertura para outros olhares, investigando sobre outros aspectos dirigidos essa temática.

Por fim, o quinto núcleo, “outros”, congregou o FT17, onde as autoras explicitaram um estudo sobre um tipo de "Estado da Arte" intitulando-o como um processo criativo e exemplificam essa proposta com a busca de pesquisas sobre Modelagem Matemática. Embora reconheçamos a relevância de estudos mais exploratórios, em que se busque levantar dados estatísticos acerca de qualquer área de conhecimento, o enfoque dado pelas autoras nos mostra, além de outro modo de investigar, que é preciso avançar no sentido de interrogarmos o que tal levantamento indica em termos de consolidação da pesquisa em Modelagem Matemática.

Assim, ele poderia expressar um modo pelo qual seria possível suprimir a "[...] necessidade da comunidade de pesquisadores em saber quais os temas têm sido estudados e as demandas e necessidades para pesquisas futuras" (OLIVEIRA, A., p. 38), aproximando-se, por exemplo, das pesquisas congregadas na tendência temática modelagem matemática $e$ revisão sistemática de estudos agendada pela autora.

Explicitadas algumas compreensões acerca dos núcleos emergentes desse olhar para as produções de Modelagem Matemática publicadas na VII SIPEM, passamos às considerações finais, em que refletimos sobre a interlocução desses núcleos com outras produções semelhantes a essa que apresentamos, de âmbito internacional. 


\section{Considerações finais}

Ao refletirmos sobre a interrogação que nos moveu para a realização desse estudo: "Que núcleos temáticos da pesquisa em Modelagem Matemática emergem dos trabalhos apresentados no VII SIPEM?”, compreendemos que os núcleos temáticos discutidos na seção anterior, ao serem dialogados com a pesquisa de Oliveira, A. (2016), expressaram algumas sínteses a respeito da produção brasileira oriundas dos anais do VII SIPEM.

Considerando a participação de alguns grupos nesta edição do SIPEM, entendemos que essa produção, aqui analisada, expressa um movimento mais recente da pesquisa brasileira em Modelagem Matemática. E, os interesses manifestados delas também parecem convergir para os interesses de alguns grupos de pesquisa internacionais. Assim, o manifesto por esses núcleos revela preocupações emergentes que se aproximam da pesquisa no âmbito internacional, por exemplo, na síntese apresentada por Barquero, Carreira e Kaiser (2017).

Essas autoras ao apresentarem uma introdução aos trabalhos do Grupo de Trabalho Temático 6 sobre Aplicações e Modelagem do X Congresso da Sociedade Europeia de Pesquisa em Educação Matemática (CERME), realizado em 2017, argumentaram que são várias as discussões desencadeadas sobre a Modelagem Matemática, as quais puderam ser concatenadas em cinco perspectivas 57 : i) perspectiva matemática; ii) perspectiva cognitiva; iii) perspectiva curricular; iv) perspectiva instrucional; v) formação de professores, já que as preocupações vão desde aspectos teóricos e epistemológicos da Modelagem Matemática às questões mais pragmáticas.

Segundo Barquero, et al. (2017), em geral, as pesquisas têm discutido sobre a relação entre a tarefa de modelar, isto é, o papel que exerce o modelador matemático profissional e o papel que o estudante desempenha na atividade de Modelagem Matemática em sala de aula; as estratégias, barreiras e competências cognitivas na experiência de Modelagem Matemática; o significado e urgência da inserção da Modelagem Matemática no currículo; e, sobre como implementar ambientes eficazes de Modelagem Matemática, tendo a interface com os materiais curriculares e o uso de tecnologias. Esse debate acerca dos materiais curriculares foi identificado por Oliveira, A. (2016) nas edições do SIPEM analisadas pela autora, inclusive, agendou a necessidade da demanda de pesquisas "[...] que investiguem como materiais podem apoiar as práticas pedagógicas em modelagem” (idem, p. 40). Contudo, na VII edição, esse tema ainda não se mostrou com expressividade.

Além de esses temas de investigação, discussões acerca da Formação de Professores em Modelagem Matemática também é um tema que tem ganhado destaque na Europa, assim como revelou o núcleo temático "Formação em Modelagem Matemática" de nossa análise,

57 Segundo as autoras, essas perspectivas foram assumidas segundo Cai et al (2014). ISSN 2526-2882 
esse tema parece fomentar debates frutíferos para a área. Barquero, Carreira e Kaiser (2017) afirmaram que:

[...] os professores e seu papel no ensino e na formação de professores desempenharam um papel proeminente no trabalho do TWG de Aplicações e Modelagem. Isso foi integrado em vários temas, como estratégias de modelagem, intervenções de professores e crenças dos professores. Essa mudança mostra um claro desenvolvimento adicional das discussões e do trabalho do GTT 6 e precisa ser fomentado e ampliado. Os professores e sua educação são a chave para a integração efetiva e eficiente da modelagem matemática na educação matemática em vários níveis (idem, p. 883, tradução nossa).

Além do reunido por essa síntese, alguns dos trabalhos de Modelagem Matemática que foram apresentados no XIII Congresso Internacional de Educação Matemática (XIII ICME), os quais constituíram um livro ${ }^{58}$, também se abrem como um movimento da pesquisa realizada em alguns países indicando, portanto, um movimento acerca da pesquisa internacional em Modelagem Matemática. Neste livro, Brown e Ikeda (2019), ao se inteirarem dessas produções dispostas em capítulos, classificaram-nas em duas linhas de investigação: uma teórica e, outra empírica. Eles alegaram que há preocupação com a compreensão da própria Modelagem Matemática, pois, parece prevalecer um interesse de tê-la como um veículo para aprender Matemática, ao invés de atividade humana de compreensão do mundo.

Dessa compreensão, da explicitação dos modos pelos quais a Modelagem Matemática se mostra como presença nos trabalhos e se articula às linhas pré-estabelecidas, os autores depreendem algumas linhas futuras para investigações, onde expuseram que os esforços devem se concentrar em "[...] mais pesquisas com modeladores experientes, o impacto do posicionamento dos próprios professores como modeladores, intervenções estratégicas dos professores durante a modelagem, subcompetências, metacognição antecipatória, verificação e validação" (BROWN; IKEDA, 2019, p. 247, tradução nossa).

Segundo esses autores, o desenvolvimento de pesquisas com modeladores experientes está associado à inserção da Modelagem Matemática no currículo e adoção dela pelos professores, incitando que a experiência é fruto da vivência de modo regular e que isso precisa ser viabilizado. Outro aspecto diz da investigação sobre os impactos que teriam os professores resolverem tarefas de Modelagem Matemática antes de incorporá-las à prática, refletindo sobre dificuldades e desafios dos estudantes. Segundo eles, poderia ser um caminho para concretizar a intenção de:

“[...] minimizar a contribuição do professor e maximizar a independência do estudante, os professores devem considerar intervenções estratégicas [...]

${ }^{8}$ STILLMAN, G. A.; BROWN, J. P. (Eds.) Lines of Inquiry in Mathematical Modelling Research in Education. Springer, 2019. 
incluiria respostas do professor como: Você consegue imaginar a situação? Qual é o seu objetivo? O que mais você precisa saber? O que esse resultado (provisório) significa em termos da situação real?” (BROWN; IKEDA, 2019, p. 248, tradução nossa).

Ainda, explicitaram que pesquisas devem priorizar a matematização desenvolvida por estudantes (iniciantes e experientes) em situações de Modelagem Matemática, com intuito de investigar processos (meta)cognitivos sobre o modo pelo qual os estudantes encaram determinada situação, quando "[...] prenunciam o que poderia ser útil matematicamente no progresso de um dado problema, tomando decisões e implementando ações para trazer o que se esperava para fruição" (idem, p. 248, tradução nossa). E, por fim, pesquisas que investiguem sobre a definição de verificação e da validação, no contexto das práticas com Modelagem Matemática.

Dessas discussões, compreendemos que temas concatenados pelas pesquisas apresentadas nos mostram uma convergência entre os debates formalizados no Brasil e em outros países, bem como, o reconhecimento das lacunas e de suas implicações para que a Modelagem Matemática se torne mais efetiva nos contextos educacionais, portanto, um interesse global desses grupos. Ao serem articulados nessa discussão, nossa intenção não foi demarcar ou estabelecer as fronteiras entre a pesquisa brasileira e a internacional, mas refletirmos enquanto comunidade de Modelagem Matemática sobre os fenômenos que têm sido investigados nos diferentes contextos, já que os núcleos revelados por essa pesquisa nos deram essa abertura ao diálogo.

Em síntese, o estudo que realizamos indica que há um movimento convergente do debate sobre os temas dirigidos à Modelagem Matemática como prática e linha de investigação no Brasil, com a estabelecida em outros países, ainda que em relação a alguns temas isso se mostra de modo mais acentuado e, em outros, mais timidamente. Tanto que as pesquisas têm sido desenvolvidas com olhares para os diferentes níveis de ensino, desde o Ensino Fundamental ao Ensino Superior, assim como, a emergência de novos temas, como "[...] o afeto e a modelagem, e a relação da alfabetização matemática com a modelagem" (BROWN; IKEDA, 2019, p. 250-251, tradução nossa), a própria avaliação em Modelagem Matemática, entre outros, que nos parecem sugestivos e comuns para os diferentes grupos.

Além das reflexões sobre esses núcleos e temas emergentes, outras reflexões também fizeram sentido no escopo desse texto já que estamos discutindo sobre a pesquisa em Modelagem Matemática. Um exemplo delas é sobre a presença dos grupos atuantes em Modelagem Matemática no Brasil, direcionado à permanência e/ou constituição de novos grupos de pesquisa interessados nesse debate. Se olharmos para as pesquisas apresentadas no SIPEM sob as quais analisamos, emerge a participação de pelo menos oito grupos de pesquisa coordenados por professores pesquisadores de diferentes regiões do Brasil. 
Entendemos que essa discussão é relevante à medida que abre caminhos para refletirmos a respeito dos FTs emergentes, já que compreendemos que a dinâmica do SIPEM é congregar os diferentes interesses dos distintos grupos. Diante disso, refletimos sobre uma dinâmica em que ocorra a participação de um maior número de pesquisadores vinculados aos diferentes grupos de pesquisas em Modelagem Matemática no país, de modo a expressar a produção científica brasileira, para que outras novas possibilidades de diálogo com o contexto internacional possam ser estabelecidas.

Parece ser eminente essa reflexão para que consigamos congregar a participação dos diferentes grupos de pesquisa e, talvez, uma alternativa seja a mencionada por Oliveira (2016), da possibilidade de criar programas de pesquisa em rede, de modo que seja possível refletirmos coletivamente sobre os delineamentos da pesquisa em Modelagem Matemática no Brasil, garantindo permanência dos avanços, de conquistas e de visibilidade acadêmica.

\section{Referências}

ALLEN, D. (Eds.), Proceedings of the Joint Meeting of PME 38 and PME-NA 36 (Vol. 1, pp. 145-172). Vancouver, Canada: PME. 2014.

ARAÚJO, J. de L. Pesquisas sobre Modelagem em eventos científicos recentes de Educação Matemática no Brasil. In: SEMINÁRIO INTERNACIONAL DE PESQUISA EM EDUCAÇÃO MATEMÁTICA, 4., 2009, Taguatinga. Anais... Taguatinga: UCB, 2009. p. 1-14.

BARBOSA, J. C.; ARAÚJO, J. L.; CALDEIRA, A. D. Modelagem Matemática: relatório das sessões do GT 10. In: SEMINÁRIO INTERNACIONAL DE PESQUISA EM EDUCAÇÃO MATEMÁTICA, 4., 2009, Taguatinga. Anais..., Taguatinga, 2009, p. 18. Disponível em: http://www.sbem.com.br/gt1o/pdf/relatorio_ivsipem.pdf. Acesso em: 1 jun. 2019.

BARQUERO, B; CARREIRA, S; KAISER, G. TWGo6: Aplicações e modelagem Introdução aos artigos do TWGo6: Aplicações e modelagem. In: CONGRESSO DA SOCIEDADE EUROPÉIA DE PESQUISA EM EDUCAÇÃO MATEMÁTICA, 10., 2017, Dublin. Anais..., Dublin, Irlanda. 2017. Disponível em: https://hal.archives-ouvertes.fr/hal01933496/document. Acesso em: 02 jun. 2019.

BROWN, J. P.; IKEDA, T. Conclusions and Future Lines of Inquiry in Mathematical Modelling Research in Education. In: STILLMAN, G. A.; BROWN, J. P. (Eds.) Lines of Inquiry in Mathematical Modelling Research in Education. Springer, 2019, p. 233253.

CAI, J., CIRILLO, M., PELESKO, J. A., BORROMEO FERRI, R., BORBA, M., GEIGER, V., .... KWON, O. N. Mathematical modelling in school education: Mathematical, cognitive, curricular, 
DENZIN, N. K.; LINCOLN, Y. S. A disciplina e a prática da pesquisa qualitativa. In:

O planejamento da pesquisa qualitativa: teorias e abordagens. Porto Alegre: Artmed, 2006, p.15-41.

instructional, and teacher education perspectives. In: LILJEDAHL, P.; NICOL, C.; OESTERLE, S.;

KLÜBER, T. E.; BURAK, D. Sobre a pesquisa em Modelagem na Educação Matemática brasileira. Diálogo Educacional, Curitiba, v. 14, n. 41, p. 143-163, 2014.

KLÜBER, T. E.; TAMBARUSSI, C. M.; LOUREIRO, D. Z.; WICHNOSKI, P.; OLIVEIRA, W. P. Rumos e avanços da Modelagem Matemática na Educação Matemática Brasileira: um olhar sobre a pesquisa a partir dos resumos do V SIPEM. Indagatio Didactica, Aveiro, v. 7, n.1, p. 80-95, jul. 2015.

OLIVEIRA, A. M. P. de. Uma agenda de pesquisa para a Modelagem Matemática brasileira. In: ENCONTRO PARANAENSE DE MODELAGEM NA EDUCAÇÃO MATEMÁTICA, 7, 2016, Londrina, PR. Anais... Londrina: UEL e UTFPR. 2016, p. 33-43.

OLIVEIRA, W. P.; KLÜBER, T. E. Formação de professores em Modelagem Matemática: uma hermenêutica dos relatórios do GT 10 - Modelagem Matemática da SBEM. Educação Matemática Pesquisa. v. 19, n. 2, 167-186, 2017.

SILVEIRA, E. Modelagem Matemática em Educação no Brasil: entendendo o Universo de Teses e Dissertações. 2007. 197 f. Dissertação (Mestrado em Educação) Universidade Federal do Paraná, Curitiba, 2007.

TAMBARUSSI, C. M.; KLÜBER, T. E. Focos da pesquisa stricto sensu em Modelagem Matemática na Educação Matemática brasileira: considerações e reflexões. Educação Matemática Pesquisa, São Paulo, v. 16, n. 1, p. 209-225, 2014.

\section{Biografia Resumida}

Lilian Akemi Kato: Licenciada em Matemática pela Universidade Estadual de Maringá - UEM (1992), Mestre em Matemática Aplicada pela Universidade de São Paulo - USP (1996), Doutora em Matemática Aplicada pela Universidade Estadual de Campinas - UNICAMP (2004) e pós-doutoramento na Universidade Estadual Paulista Júlio de Mesquita Filho, UNESP-RC. É professora no Departamento de Matemática da UEM e do Programa de Pós-Graduação em Educação para a Ciência e a Matemática e coordenadora do Grupo 
Interdisciplinar de Estudos em Modelagem na Educação Matemática - GIEMEM.

Contato: lilianakemikato@gmail.com

Link para Lattes: http://lattes.cnpq.br/6356641105245996

Wellington Piveta Oliveira: Licenciado em Matemática pelo Centro Técnico-Educacional Superior do Oeste Paranaense CTESOP (2011). Especialista em Ensino de Ciências e Matemática pela Universidade Estadual do Oeste do Paraná UNIOESTE (2014), Mestre em Educação pela UNIOESTE (2016) e Doutor em Educação para a Ciência e a Matemática pela Universidade Estadual de Maringá - UEM (2020). Atualmente é professor do curso de Licenciatura em Matemática na Educação à Distância do Centro Universitário de Maringá - UNICESUMAR e integrante dos Grupos de Pesquisa: Grupo Interdisciplinar de Estudos em Modelagem na Educação Matemática - GIEMEM e Formação de Professores de Ciências e Matemática - FoPeCiM.

Link Lattes http://lattes.cnpq.br/2507355844545944

e-mail: wellingtonmat09@hotmail.com 